\title{
Estudos em Seminário Permanente
}

\author{
ALDO V. DE MAGALHÃES \\ Prof. de Técnica de Jornal e Periódico \\ na Universidade de Brasília
}

Uma experiência realizada na Universidade de Brasília, na Faculdade de Comunicação, talvez possa conduzir os professôres a um sistema de maior rendimento na matéria que devem ministrar e os alunos a uma participação bem mais eficiente nas atividades curriculares.

O Seminário Permanente de Comunicação nasceu de observação da necessidade cada vez maior de os professôres se comunicarem com os alunos fora da área extremamente formal de suas aulas regulares. Por mais que procuremos evitar a formalidade em tais aulas, estamos sempre amarrados a um "programa a cumprir" e a uma condição de mera concessão quando procuramos fazer com que os alunos tenham real participação

A idéia de se reunirem elementos que buscam determinados resultados em um campo especializado do conhecimento humano através do debate e pesquisas proporcionado pelo tipo de atividade chamada "seminário", é aplicável, evidentemente, não apenas na Universi-
dade.

Muitas promoções na área do Serviço Público nos têm demonstrado os bons resultados de tal trabalho.

A sugestão de algo "permanente", onde periòdicamente se possa colocar um problema para debater e pesquisar, é a decorrência da experiência que passamos a relatar. Grupos que trabalhem de quando em quando utilizando o sistema de seminário, desenvolvendo atividades criadoras e examinando pequenas etapas de um trabalho global que se propõe numa estrutura administrativa, podem constituir resposta para os des- vios de rotinas e até mesmo para o desinterêsse que não raro assalta o funcionário em seu setor de atividade.

No geral as técnicas mais avançadas de reuniões têm sido utilizadas por pequenos grupos dirigentes, e seus ensinamentos inesgotáveis nem sempre chegam ao funcionário que em realidade executa os planos e se torna responsável pelo bom ou mau funcionamento de uma repartição. E precisamente êste funcionário pode ser o fator determinante de um eventual "sentimento de hostilidade" (1).

\section{PONTO DE PARTIDA}

Louvados em experiências anteriores, realizadas no Rio Grande do Sul e em Brasília, os promotores do Seminário Permanente de Comunicacão procuraram evitar tôda formalidade e conduzir os temas em estudo exclusivamente de acôrdo com a programação feita pelos alunos. $\mathrm{E}$ foi pedido que tal programação se realizasse a cada passo de sua execução, oferecendo alternativas com extraordinária liberdade.

A própria participação do dirigente, na qualidade de coordenador, procurou criar as condições de "liderança democrática" para obter maior motivação e na esperança de que os trabalhos dos grupos fôssem "progressivamente mais produtivos" (2).

A programação nestes moldes nos pareceu evitar se chegasse às mesmas obrigações e formalidades da aula tradicional. No momento em que o "projeto seminário" foi lançado pairava entre os alunos, e mesmo entre o corpo docente, uma terrível indagação sôbre a viabilidade de executar programas rígidos em 
disciplinas muitas vêzes mal estruturadas ou insuficientemente exploradas.

No campo da Comunicação Social muita pesquisa está por fazer. Entre os trabalhos de pesquisa já realizados muitos carecem de valor pelas condições precárias em que foram executados e nem todos, mesmo os bons, se aplicam inteiramente às condições de vida e trabalho da gente brasileira.

Prova da insegurança quanto ao que mais convém a uma Faculdade de Comunicação é a dificuldade em se fixar um programa suficientemente abrangente das modalidades hoje tão variadas do processo de comunicação. Oficialmente ainda não existe tal programa. $\mathrm{E}$ até ficarmos inteiramente livres da idéia da mensagem escrita como único meio de comunicação, muitos programas serão feitos, debatidos e inutilizados.

Buscar idéias, e para cada idéia estabelecer um programa de debates e pesquisa, era, portanto, uma necessidade fundamental.

\section{O PROCESSO DE CRIATIVIDADE}

As atividades do Seminário tiveram início com um breve curso sôbre criatividade, baseado nas lições de Alex Osborn (3). Logo depois, utilizando as técnicas por êle recomendadas, foi organizada uma pauta de assuntos que poderiam merecer estudo e debate no Seminário.

O Seminário foi organizado em grupos de trabalho e distribuído nos horários dos alunos de acôrdo com suas necessidades particulares, já que o sistema utilizado na Universidade de Brasília permite ao aluno livre escolha de disciplinas por semestre. Cada grupo não reuniu número superior a dez alunos, para que o trabalho se desenvolvesse com mais eficiência. Êste número, aliás, deveria ser mantido em todo o trabalho feito à maneira de seminário. Êle se relaciona diretamente com a necessidade de participação de cada integrante do grupo. Neste sistema não se busca a lavratura de atas, nem a publicação de anais e muito menos a apresentação de teses. Interessa única e exclusivamente a participação de cada um em cada assunto. Todos têm uma contribuição a oferecer. Esta contribuição é muitas vêzes forçada ao início, mas surgirá como decorrência da satisfação de participar, sempre que se conduza com propriedade um seminário.
Por esta condição, além de outras, casa-se admiràvelmente o tipo de trabalho em seminário com as técnicas básicas das "reuniões de criatividade" de Osborn, embora não se deva estabelecer confusã̃o entre uma coisa e outra. Mas as estruturas, quando postas em funcionamento, permitem até alternância de atividade com resultados que de modo geral são surpreendentes.

No caso em exame - da Faculdade de Comunicação - foram criados muitos grupos de trabalho, até mesmo pela necessidade de não excluir alunos que poderiam se beneficiar com a experiência. Depois de algumas semanas de funcionamento dos grupos, no entanto, foram cancelados aquêles que mostraram irregularidade de comparecimento ou funcionamento precário por qualquer outro motivo. Isto reduziu o total de alunos participantes, mas ofereceu melhores condiçôes de trabalho por grupo. Por outro lado, até mesmo o número ideal de dez por grupo nem sempre foi mantido, pois se tratava de experiência de cuja aceitação não tínhamos uma previsão possivel, e tôda rigidez poderia conduzir ao malôgro.

\section{EM FUNCIONAMENTO}

O encadeamento de tarefas e as sugestões ocorridas nos trabalhos dos grupos ofereceram resultado muito acima da expectativa. No primeiro momento, talvez algumas dúvidas relacionadas com a eficiência do sistema tenham determinado reservas quanto à participação dos alunos. Mas à medida em que os primeiros resultados surgiram, operou-se uma mudança de atitude. Mesmo alguns alunos de fraca participação em trabalhos de aula encontraram condições favoráveis para uma participação mais efetiva no Seminário.

Procuramos respeitar o princípio de que o objetivo maior do Seminário é oferecer oportunidade para debates e pesquisas pessoais sôbre temas escolhidos na área de estudo. No caso, na área da Comunicação Social.

Um livro que se resume e cujo conteúdo é transmitido aos demais durante uma reunião, o levantamento de títulos existentes na biblioteca sôbre determinado assunto, a organização de um departamento de pesquisa de informação ou um arquivo são temas básicos para - trabalho dos grupos. Enquanto o assunto oferecer rendimento, o grupo prossegue trabalhando nêle. Com fre- 
qüência, passa para uma atividade não prevista, pela necessidade de dar seqüência lógica ao tema básico ou aperfeiçoar técnicas recomendadas para a sua plena realização.

Exemplo de como "assunto puxa assunto" no sistema de seminário é o grupo que resolveu estudar técnicas de pesquisa e entrevista.

De início julgou conveniente fazer um contato com o pessoal da Biblioteconomia para receber nocões fundamentais de organização de índices e referências. Bem acolhidos no setor, tiveram a promessa de palestra com um dos monitores para colocação mais extensa dos problemas ligados a técnicas de pesquisa e arquivo. A palestra foi boa, determinou interêsse do grupo, e foi transformada em um cursinho de quatro aulas e visita à biblioteca para conhecer o que o leitor comum não vê: como funciona a equipe que organiza, numera, ficha, põe em índice todos os volumes de uma biblioteca.

Não obstante o trabalho realizado, o grupo considerou ainda conveniente pedir a um colega que dois anos antes fizera estágio no Departamento de Pesquisa do jornal o Estado de São Paulo, uma palestra sôbre problemas específicos de organização de arquivo em jornal. Foi a pincelada final no quadro de conhecimentos que os moveu a tomar conta do arquivo já existente na Faculdade de Comunicação e abandonado desde algum tempo.

Quando o grupo, finalmente, perguntou qual seria o próximo assunto a encaminhar, verificou, com certa alegria, que a pauta do primeiro trabalho ainda não havia sido esgotada: técnicas de pesquisa e entrevista. Para o trabalho de técnica de entrevista já havia um arquivo em funcionamento razoàvelmente atualizado.

Para êste grupo, muitas das dificuldades surgidas ou que talvez surgissem no futuro nas disciplinas de técnica jornalística ou similares, foram resolvidas no trabalho do Seminário. Da mesma forma como dificuldades de execução de ordens no Serviço Público podem encontrar encaminhamento brilhante quando se reúne a capacidade de pensar e de examinar problemas distribuída num grupo pequeno que muitas vêzes oferece resistência natural à execução de um programa, pelo fato inteiramente compreensivel de não ter participado de sua criação.

\section{ADAPTAÇÃO CURRICULAR}

A inclusão do Seminário Permanente nas atividades da Faculdade de Comunicação para o semestre seguinte àquele em que se realizou a experiência-pilôto foi autorizada pelo Conselho Departamental, que a considerou útil. Mas ainda não foram bem estabelecidas as condições em que tal atividade pode ser adaptada ao curriculo. Particularmente no que se refere à conveniência de atribuir mençóes e carga-horária ao trabalho realizado no Seminário.

Acreditamos que um trabalho como êste possa ser considerado como atividade complementar do aluno e tenha valor como hora/trabalho, ou um similar do estágio, ambos previstos na legislação do ensino superior e muito de acôrdo com as recomendações do grupo de trabalho que estudou a reforma universitária (4).

Entre as providências estudadas para prosseguimento eventual das atividades do Seminário, ou de atividades calcadas na experiência feita, figura a ampliação do curso sôbre criatividadé pelo processo de agitação de idéias (Osborn) (5) e sua obrigatoriedade. Os alunos que não realizassem o curso integralmente (cêrca de oito ou doze horas) não poderiam permanecer no Seminário. Isto seria possível porque o caráter não obrigatório do Seminário tem duplo objetivo: não criar embaraços à livre organização do horário do aluno e evitar a permanência daqueles que não tenham efetivo interêsse nesta atividade universitária complementar.

Vale, no entanto, observar que temos notado dificuldade acentuada na realização de atividades que não possam ser computadas por menções, horas/aula ou horas/trabalho. Isto nos parece ocorrer de maneira quase dramática no campo de nossa atividade de comunicadores. Talvez mesmo pela natureza da vocação: é preciso elaborar um jornal e fazê-lo circular; escrever um programa de rádio e fazê-lo ouvido. É preciso pesquisar e debater um problema e ver o resultado computado numa ficha de rendimento.

Daí a sugestão no sentido de que a atividade seja considerada como estágio ou de forma a pesar na atividade curricular do aluno de maneira expressiva, embora muitos a tenham considerado satisfatória pelo que oferece como importante abertura para um sistema de estudo motivado e amplo. 


\section{PERSPECTIVAS}

Não obstante a experiência se ter realizado num dos momentos mais conturbados da Faculdade de Comunicação, as perspectivas para o desenvolvimento da idéia parecem ser muito boas. Nenhum dos professôres convidados a participar do Seminário se negou a colaborar. Isto é significativo particularmente se salientarmos que o maior número de convites foi feito para professôres com exercício em outras unidades da Universidade, embora contássemos com a participação efetiva de todos os professôres da própria Faculdade de Comunicação.

Um curso especial acrescentado aos programas curriculares da Faculdade nasceu diretamente dos contatos estabelecidos durante os trabalhos do Seminário. E vários professôres da Faculdade declararam seu interêsse em realizar contatos à maneira de seminário, com seus alunos, para desenvolver idéias e debater aspectos do programa em desenvolvimento nas respectivas disciplinas.

Embora seminários se possam realizar a qualquer momento, muito mais fácil é a realização quando já existe uma estrutura montada permanentemente. $\mathrm{Na}$ Faculdade de Comunicação foi reservada uma sala com distribuição de mesas e cadeiras especialmente estudada para os trabalhos do Seminário. Isto incorpora ainda mais fàcilmente a atividade aos demais compromissos do currículo, e nisto difere, fundamentalmente, a experiência realizada das promoções, muitas vêzes, inadequadamente solenes que se realizam com a denominação genérica de seminário.

Por outro lado, o caráter flexível da programação do Seminário permite realização de planos altamente estimulantes. Muitos alunos que ainda não tinham recebido informação sôbre o Centro de Ciência de Computadores existente na Universidade, tiveram oportunidade de realizar experiências com computadores sob a orientação do professor encaregado do Centro.

Através do Seminário Permanente de Comunicação, o processo de integração previsto no Plano Orientador da Universidade de Brasília se torna uma realidade, que cada aluno pode usufruir quando resolver. Mesmo numa estrutura aberta e flexível como a desta Universidade, os entraves curriculares e as obrigações inevitáveis dos programas e horários são muitas vêzes dificuldades a uma perfeita integração. O Seminário poderia oferecer um caminho saudável e estimulante para contornar tais dificuldades.

\section{NOT A S}

(1) J. KLEIN - O Trabalho de Grupo - Zahar Editôres, Rio, 1968, 2.a ediçăo, pág. 82.

(2) MALCOLM e HULDA KNOWLES - Introduçăo à Dinâmica de Grupos - Lidador, Rio, 1967 , págs. 54 a 57 .

(3) ALEX F. OSBORN - O Poder Criador da Mente - Ibrasa, Săo Paulo, 1965.
(4) Relatório do Grupo de Trabalho sôbre a Reforma Universitária - MEC, 1968, págs. $37 / 38$.

(5) EUGENE VON FANGE - Criatividade Profissional - Ibrasa, Sắo Paulo, 1966, 2. ${ }^{\text {a }}$ ediçăo, págs. 46 e seguintes. 